\title{
O CHAIN ROMANCE DWORKINIANO E AS PRIVATIZAÇÕES BRASILEIRAS: EM DEFESA DO RECONHECIMENTO DAS TEORIAS ECONÔMICAS COMO FONTES FORMAIS OPCIONAIS DO DIREITO
}

\author{
Alexandre Müller Fonseca ${ }^{1}$
}

\begin{abstract}
Resumo
Este artigo argumenta que as decisões judiciais justificadas por meio de casos precedentes não podem ser replicadas para qualquer caso. Sustenta-se que esse tipo de raciocínio jurídico pode ocasionar implicações diferentes daquelas esperadas. O artigo se contrapõe ao chamado "romance em cadeia" de Ronald Dworkin, alegando que o uso de teorias conexas ao Direito para auxiliar na resolução de um caso que reivindique elementos externos ao domínio estritamente legal é explicativamente superior. Dito isso, defende-se que as teorias conexas ao Direito, tal qual ocorre com a doutrina jurídica, sejam reconhecidas enquanto fontes opcionais do Direito.
\end{abstract}

Palavras-chave: Ronald Dworkin; Romance em Cadeia; Doutrina; Fontes do Direito.

\section{INTRODUÇÃO}

Ao longo de sua produção intelectual, Ronald Dworkin teceu diversas críticas ao positivismo jurídico defendido por Herbert Hart. ${ }^{2}$ Dentre essas críticas está o ataque à discricionariedade judicial implicada pelo seu positivismo. De acordo com Hart, o Direito, assim como qualquer outra ciência, é estruturado por meio de regras que, inevitavelmente, são expressas por meio da linguagem. Haverá casos em que não se têm maiores dúvidas se determinada regra se aplica, casos em que é claro - à luz da linguagem comum ou da linguagem técnica - que certos predicados são verdadeiros no que concerne à "cadeira", do mesmo modo que há casos claros para a aplicação de "mandado de injunção". Todavia, há casos em que não se têm, a priori, respostas prontas ou evidentes a fornecer. Nesses casos, o juiz exerceria sua discricionariedade, determinando se a regra prevista se aplica ao caso. Contra a possibilidade de que um magistrado possa vir a decidir um caso de acordo com sua compreensão pessoal do que seria o certo ou justo é que Dworkin propôs uma alternativa para a fundamentação judicial, visando minimamente constranger um possível decisionismo do jurista.

Neste artigo, questiona-se a pertinência do receituário sugerido por Dworkin com seu "romance em

\footnotetext{
${ }^{1}$ Doutorando em Filosofia pela Durham University (UK) onde integra o CHESS (Centre for Humanities Engaging Science and Society).Bolsista CAPES.E-mail: alexandre.m.fonseca@durham.ac.uk
} 
cadeia” para auxiliar na resolução de um caso concreto. Por meio de um caso histórico brasileiro, as privatizações ocorridas ao longo dos anos 1990, argumenta-se que o uso de precedentes judiciais (uma consequência normativa extraída do raciocínio de Dworkin em caso de unidade de decisões passadas sobre uma mesma matéria) como meio de solução de litígios não deve ser usado como elemento justificador para todo e qualquer caso, uma vez que as consequências podem ser diametralmente distintas daquelas previstas. Neste artigo, defendese que as teorias desenvolvidas pelas demais ciências conexas ao Direito (Sociologia, Economia etc.) possam ser reconhecidas enquanto fontes acessórias e opcionais do Direito, capazes de auxiliar na resolução de litígios legais.

Alguns autores como Jules Coleman (1980, 1988), Avery Katz (1998), Jeffrey Harrison (1995) e Richard Posner $(1981,2014)$ defendem que a Economia (mais propriamente, as ferramentas da microeconomia) seja (a) usada para explicar o direito e que (b) as regras legais deveriam ser pensadas como os meios capazes de promover a eficiência econômica (no sentido ótimo paretiano) nas interações entre os diversos atores sociais nos termos de troca (ou contratos) por eles estabelecidos. ${ }^{3}$ A argumentação aqui desenvolvida não está comprometida com essa perspectiva. Neste artigo, defende-se a possibilidade de auxílio das teorias externas ao Direito - no caso em questão, a Economia - como meio acessório para a busca da melhor solução possível nos casos em que as leis se remetem explicitamente a questões econômicas. E, para que isso seja possível, alega-se que tais teorias possam ser reconhecidas como fontes opcionais à lei, tal qual ocorre com a doutrina jurídica. ${ }^{4}$

A discussão é tratada do seguinte modo. Na primeira seção deste artigo (seção 1), apresenta-se a hipótese estética dworkiniana, demonstrando a razão pela qual seu argumento é insuficiente para lidar com casos que se reportem explicitamente a questões externas ao Direito. E, em seguida (seção 2), expõe-se uma forma explicativamente superior para lidar com o tipo de matéria aqui proposta. Defende-se aqui que o uso dessas teorias externas às elaborações doutrinárias deveriam ser pensadas enquanto fontes formais opcionais do Direito toda a vez que a lei fizer menção explícita a debates cujo conteúdo foge ao domínio estritamente legal.

\section{A METÁFORA DO ROMANCE EM CADEIA}

Foi em Uma questão de princípio (2001 [originalmente publicado em 1988]) que Dworkin propôs um modelo normativo que visava evitar ou, pelo menos, constranger um possível voluntarismo de um juiz na hora de decidir um caso concreto. Para isso, ele elaborou uma metáfora em que aconselha como o juiz deveria olhar para

\footnotetext{
${ }^{2}$ As obras mais expressivas de Dworkin em que ele criticou Hart ainda são O império do direito (2007 [1986]) e Uma questão de princípio (2001 [1988]). Muitas das críticas encontradas nas obras daquele período são reforçadas em obras mais tardias de Dworkin. A título de exemplo, ver seu Justiça de toga (2010 [2006]).

${ }^{3}$ Para um resumo sobre a abordagem econômica do direito, ver Kornhauser (2011).
} 
sua atividade profissional. O jurista deveria se imaginar como um autor de um capítulo de um romance escrito coletivamente. A sentença que ele proferirá deveria ser mais um capítulo desta "obra". Tal qual em um romance em que cada capítulo subsequente apresenta uma coerência com os capítulos passados, o juiz deveria buscar escrever seu "capítulo" de forma coerente com os demais, respeitando aquilo que seus pares produziram (no caso do direito, decidiram) no passado:

Cada juiz é como um romancista na corrente. Ele deve ler tudo o que os outros juízes escreveram no passado, não apenas para descobrir o que escreveram, mas para chegar a uma opinião sobre o que esses fizeram coletivamente, da maneira como cada um de nossos romancistas formou uma opinião sobre o romance coletivo escrito até então. Qualquer juiz obrigado a decidir uma demanda descobrirá, se olhar nos livros adequados, registros de muitos casos plausivelmente similares, decididos há décadas ou mesmo séculos por muitos outros juízes, de estilos e de filosofias jurídicas e políticas diferentes, em períodos nos quais o processo e as convenções judiciais eram diferentes. Ao decidir o novo caso, cada juiz deve considerar-se como parceiro de um complexo empreendimento em cadeia, do qual as inúmeras decisões, estruturas, convenções e práticas são a história; é seu trabalho continuar essa história por meio do que ele faz agora. [...] Portanto, deve determinar, segundo seu próprio julgamento, o motivo das decisões anteriores, qual realmente é, tomado como um todo, ou tema da prática até então. (DWORKIN, 2001, p. 238)

Isso não quer dizer que seu modelo se comprometa com a existência de fatos ou dados brutos históricos que levariam um juiz a replicá-los. Como o próprio Dworkin advertiu, não há um algoritmo para decidir um litígio de forma correta (DWORKIN, 2001, p. 240). A metáfora soa mais como um alerta a um possível desleixo de um magistrado que, por ventura, dê às costas àquilo que seus pares falaram sobre a matéria que ele (juiz) agora julga. O intuito explícito é constranger possíveis vontades próprias do julgador. Com essa prescrição como norte limitador, em virtude da dimensão quantitativa do material jurídico recolhido (materiais legais e decisões passadas) e interpretado pelo juiz, espera-se um maior grau de previsibilidade das decisões judiciais, já que o juiz não poderia "inventar uma história melhor" (DWORKIN, 2001, p. 240). Logo, reconhecida a ratio dicidendidos casos passados e sendo esses casos equivalentes ou análogos ao caso por ele ora julgado, o magistrado deveria olhar para si mesmo como um reprodutor daquela história. Há detalhes na formulação de Dworkin e que aqui não interessam explicitar. ${ }^{5}$ Comecemos a avaliação da pertinência do receituário dworkiniano a partir de um caso hipotético em que seja possível reconhecer uma unidade de concordância nas decisões judiciais sobre um mesmo

\footnotetext{
${ }^{4}$ Sobre o reconhecimento da doutrina enquanto fonte do Direito, ver Shecaira (2013). Para um trabalho de literatura comparada, demonstrando a influência da produção acadêmica por meio de citações explícitas nas sentenças proferidas em cortes nos EUA, França e Inglaterra, ver Duxbury (2001).

${ }^{5}$ Sobre a liberdade do intérprete ao avaliar um texto, o quão livre estaria o primeiro romancista, o quão constringido são as interpretações dos elos mais distantes em comparação com o ponto inicial e a possibilidade de um rumo distinto da cadeia no decurso do tempo, é fundamental ler os debates entre Dworkin e Stanley Fish sobre tais pontos. Como a situação aqui proposta é de uma possível convergência geral das decisões judiciais passadas sobre um mesmo assunto, não se faz necessário abordar essa discussão. Mas um bom resumo sobre o debate Dworkin-Fish, além dos próprios textos de Dworkin e Fish, pode ser conferido em Garrote (2017).
} 
tipo de matéria julgada no passado supondo que, no futuro, surja um caso análogo ou equivalente. ${ }^{6}$ Aqui, um breve resgate histórico ajudará na adequada avaliação do argumento de Dworkin, já que o raciocínio que subjaz sua proposta, assim como o raciocínio baseado em precedentes, depende de analogia. Passemos, então, ao resgate histórico.

Em 1989, ocorreu uma reunião em Washington (USA) entre membros dos organismos financeiros internacionais (FMI, BIRD e Banco Mundial) e membros do tesouro americano, reunião esta que ficou conhecida como "Consenso de Washington". Dessa reunião foram extraídas as diretrizes que países em dificuldades financeiras e fiscais daquele período deveriam seguir para reajustarem suas economias. Para que os países pudessem contrair empréstimos com essas instituições, tais organismos condicionaram a concessão dos empréstimos à aplicação da seguinte agenda econômica (no curto e médio prazo):

1. disciplina fiscal

2. redução dos gastos públicos

3. reforma fiscal

4. abertura comercial

5. privatizações

6. redução do papel do Estado

7. abolição de regulações que impedem a entrada de novas firmas ou restringem a competição. ${ }^{7}$

Estabelecida a agenda econômica e após o começo de sua implementação em diversos países, faltava ainda estabelecer uma agenda institucional que assegurasse sua eficácia. É nesse espírito que em 1996, o Banco Mundial lançou o documento técnico 319, intitulado "The judicial sector in Latin America and the Caribbean: elements of reform". Esse documento trazia uma série de orientações a serem tomadas pelos países desde o orçamento adequado ao judiciário até os modos como os juízes deveriam ser escolhidos. Mas o ponto relevante é o objetivo central da reforma que visava criar um ambiente econômico hospitaleiro e seguro para a livre circulação de capitais:

\footnotetext{
${ }^{6}$ Sobre o romance em cadeia e sua possível aplicação prática, Cross e Lindquist (2005) realizaram um estudo de caso, avaliando diversas decisões de diferentes cortes americanas sobre um mesmo tipo de caso. A intenção dos autores era conferir se, na prática, a hipótese estética de Dworkin era aplicada. Mesmo nas cortes americanas em que os precedentes possuem uma relevância maior que nas cortes brasileiras, os autores concluíram que a influência dos precedentes é menor do que comumente se pensa.

${ }^{7}$ Dados extraídos do sítio eletrônico da Organização Mundial da Saúde: <http://www.who.int/trade/glossary/story094/en/>. As conclusões técnicas que fundamentam tais diretrizes e embasam sua aplicação nos países latino-americanos podem ser conferidas em Williamson (1990). No Brasil, mais especificamente, em 1990, o então Presidente Fernando Collor de Mello sancionou a Lei da Desestatização do Estado brasileiro de n ${ }^{\circ} 8.031 / 90$ que estabelecia dentre seus objetivos já em seu art. $1^{\circ}$ ao defender a reordenação estratégica no Estado na economia, transferindo à iniciativa privada atividades indevidamente exploradas pelo setor público (inciso I), a busca por diminuir a dívida pública nacional (inciso II) e por atração de investimentos. Posteriormente, tal lei foi revogada pela Lei 9.491/97 durante o governo de Fernando Henrique Cardoso, a lei do chamado Plano Nacional de Desestatização (PND), que alterou alguns procedimentos estabelecidos pela lei anterior.
} 
A reforma econômica requer um bom funcionamento do judiciário o qual deve interpretar e aplicar as leis e normas de forma previsível e eficiente. Com a emergência da abertura dos mercados, aumenta a necessidade de um sistema jurídico. Com a transição de uma economia familiar - que não se baseava em leis e mecanismos formais para a resolução de conflitos - para um aumento nas transações entre atores desconhecidos, cria-se a necessidade de maneiras de resolução de conflitos de modo formal. As novas relações comerciais demandam decisões imparciais com a maior participação de instituições formais. Todavia, o atual sistema jurídico é incapaz de satisfazer essa demanda, forçando, consequentemente, as partes a continuar dependendo de mecanismos informais, relações familiares ou laços pessoais para desenvolver os negócios. (DAKOLIAS, 1996, p. 3)

Para o Banco Mundial, um judiciário ideal "aplica e interpreta leis de forma equitativa e eficiente o que significa que deve haver [...] previsibilidade nas decisões judiciais" (DAKOLIAS, 1996, p. 4). Dito isso, passemos ao caso hipotético em si.

Imaginemos que, no futuro, o governo brasileiro proponha a venda de sua principal estatal, a PETROBRÁS. Imaginemos também que essa proposta, mesmo contrariando grande parte da população brasileira - assim como aconteceu no caso da venda da Vale do Rio Doce e de outras tantas estatais durante o governo de Fernando Henrique Cardoso - seja judicializada. Se o nosso juiz fictício seguir as recomendações de Dworkin, é razoável supor que ele aprovaria a venda da estatal. Afinal, seus pares, nas esferas estaduais e federais, no passado recente, não impediram, pela via legal, as vendas de ativos e empresas públicas efetuadas por governos estaduais e pela União duas décadas atrás. A própria acusação de juiz ativista ou algo do gênero perderia sua força, já que a decisão do magistrado imaginário apenas teria corroborado com as práticas de seus pares sobre um mesmo tipo de caso. Ademais, a ancoragem da decisão futura com base nos precedentes passados revestiria a decisão de consistência formal: dois casos equivalentes sendo tratados de um mesmo modo, garantindo isonomia no tratamento. Mas note que as questões substanciais sobre esse tipo de questão - pertinência ou não da venda não são tocadas se o fundamento decisional residir exclusivamente nos precedentes. E é justamente esse tipo de argumento, os substanciais, que não podem ser - e não estão - excluídos da argumentação jurídica. ${ }^{8}$

Em Teoria da argumentação jurídica, Fábio Shecaira e Noel Struchiner (2016) fazem uma distinção entre tipos de argumentos usados no cenário jurídico. Há argumentos substanciais que apelam livremente a

\footnotetext{
${ }^{8}$ Em 1997, em uma ação popular encabeçada pelo ministro Celso de Mello, foi alegado pela parte autora que no edital que estabelecia as regras para a venda da empresa deveria constar as razóes que justificassem a venda da Vale do Rio Doce. Sobre esse ponto, as alegações que constam na peça são de natureza mista, tanto formais quanto materiais: "Reconhece-se, boamente, a situação difícil em que se encontrava aquele órgão, pois não teria mesmo como produzir uma justificativa minimamente consistente e que, pois, se tentasse fazê-lo, acabaria por demonstrar, de modo indireto, a completa ausência de razões prestantes para isto, de maneira que, ao fim e ao cabo, restaria, a mau de seu grado, revelada a sensatez, o disparate, a irresponsabilidade, o caráter gravemente lesivo a interesses nacionais básicos e o comprometimento do futuro do país. É que, como ao diante se dirá, desde Domingos Fernandes Calabar não se intentou ainda ato tão adverso ao Brasil quanto o que se substancia na pretendida venda da CVRD”. A íntegra da peça pode ser acessada em: <http://wwwl.folha.uol.com.br/fsp/brasil/fc020506.htm>. O suporte fático da peça é praticamente baseado em argumentos substanciais, inclusive mencionando a importância que a Companhia tinha no contexto social, uma vez que destinava $8 \%$ no do seu faturamento líquido a Programas Sociais de centenas de municípios brasileiros.
} 
questões morais, econômicas etc, sem fazer menção explícita aos standards legais. E há os argumentos que predominam amplamente no Direito, argumentos que Shecaira e Struchiner chamam de "institucionais", uma vez que remetem a padrões e regras estabelecidas pelo ordenamento jurídico. Antes que o leitor possa concluir que, dada a natureza da ciência jurídica, os argumentos substanciais estão - ou, pelo menos, deveriam estar fora do cenário legal - não é isto que afirmam os autores:

A tese institucional diz que a argumentação de profissionais de Direito é predominantemente institucional. Ela não diz que a argumentação desses profissionais é exclusivamente institucional. Os juízes, por exemplo, frequentemente usam argumentos substantivos. Contudo, é crucial notar que, quando os juízes recorrem a argumentos substantivos, eles normalmente o fazem com o objetivo de corroborar argumentos institucionais já formulados. Mesmo quando apelam a considerações explícitas sobre o que é justo ou bom, por exemplo, normalmente encontram meios de passar sobre essas considerações certo "verniz" institucional. Argumentos institucionais predominam no Direito: eles não reinam sozinhos, mas têm precedência sobre argumentos substantivos. (SHECAIRA; STRUCHINER, 2016, p. 39-40)

A distinção entre esses dois tipos de argumentos usados no Direito não é de gênero, mas sim de grau, e a prática jurídica flutuaria em meio a esses dois extremos argumentativos. A título de ilustração, o diagrama abaixo (Figura 1) posiciona os dois argumentos, institucionais e substantivos, em polos extremos da argumentação, e também aponta onde estaria situada a argumentação dos profissionais do direito.

\section{Figura 1 - Esquema argumentativo}

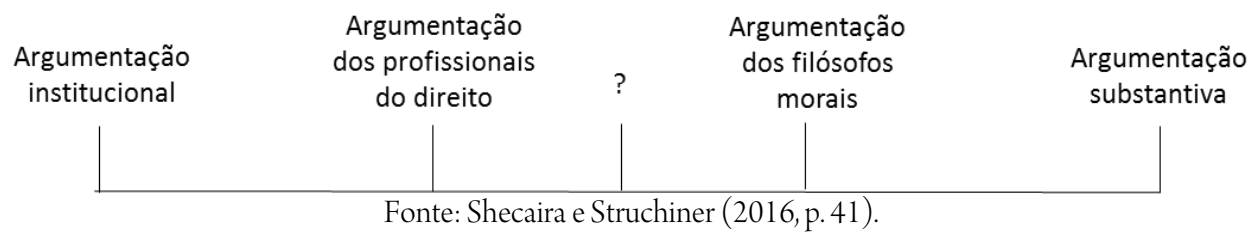

Segundo essa classificação, a argumentação dos operadores jurídicos está mais próxima dos argumentos institucionais que dos argumentos substantivos. Entretanto, dependendo do caso, os argumentos podem ser mais substantivos. ${ }^{9}$ Na prática, grande parte das argumentações dos profissionais mesclam questões institucionais com substantivas e a rotina enfrentada diariamente nos Tribunais flutua entre esses dois extremos. ${ }^{10}$ Com base nesse

\footnotetext{
9 O ponto de interrogação seria a zona de penumbra/vagueza entre os extremos, casos inclassificáveis à luz da distinção convencionada, o que não afasta a relevância da própria distinção. Shecaira e Struchiner asseveram que a distinção permanece relevante desde que "um grupo significativo de casos se aproxime de cada um dos extremos" (SHECAIRA, STRUCHINER, 2016, p. 41). A título de exemplo, não afastamos, de modo algum, a distinção entre carecas e cabeludos apenas por existirem casos concretos inclassificáveis em um polo ou em outro. Sobre a vagueza e como ela afeta o Direito, ver Endicott (2000).

${ }^{10}$ Recentemente, a juíza substituta Caroline Lima, do Tribunal de Justiça do Distrito Federal e Territórios, apontou ilegalidade na cobrança de entradas com valores distintos para homens e mulheres em festas na noite de Brasília. Em um dos trechos do julgado, a magistrada, após sustentar que a diferenciação de preços em virtude do gênero do consumidor não encontra qualquer amparo legal no ordenamento brasileiro, adicionou ainda que "[...] não pode o empresário-fornecedor usar a mulher como 'insumo" para a atividade econômica, servindo como 'isca' para atrair clientes do sexo masculino para seu estabelecimento. Admitir-se tal prática afronta, de per si, a dignidade das mulheres, ainda que de forma sutil, velada". Ver:
} 
esquema, é razoável supor que numa possível discussão acerca da venda da PETROBRÁS alguns dos argumentos mais próximos do polo substantivo favoráveis à venda da empresa poderiam ser os mesmos que eram formulados no debate público na década de 1990. Isto é, tornar a máquina pública mais eficiente, arrecadação dupla, ou seja, ganhos diretos com a venda da empresa e posteriormente por meio dos tributos a serem recolhidos pela nova prestadora de combustível, tornar a economia nacional mais internacionalizada integrando-a nas cadeias globais de valor e a própria corrupção poderia ser alegada como fundamento adicional para o enxugamento da máquina pública. ${ }^{11}$

Naquele período, a estratégia econômica elaborada para o país possuía os seguintes pilares. O primeiro era a disciplina fiscal: o Estado brasileiro deveria deixar de gastar mais do que aquilo que fosse arrecadado. ${ }^{12}$ Além da disciplina fiscal, a disciplina monetária e a desregulamentação financeira eram pré-condições para aquecer a economia e destravar os investimentos, fazendo com que a taxa de juros fosse determinada via mercado, freando, com isso, possíveis ações do Banco Central de incentivo a setores nacionais. Outra diretriz estabelecida foi a liberalização comercial e financeira com a finalidade de ampliar a concorrência dentro do próprio país, mobilizando a poupança externa que viria a reduzir o grau de manobra de políticas econômicas inadequadas. Por fim, a privatização de estatais e a desregulamentação de mercado de bens e de trabalho fechavam o eixo central da estratégia de desenvolvimento da época, que prometia elevar a competitividade e viria a gerar empregos qualificados. Todavia, na prática, alguns indicadores macroeconômicos sugerem que a reestruturação econômica do Estado brasileiro na década de 1990, durante os governos de Fernando Collor de Mello e posteriormente Fernando Henrique Cardoso, não saiu exatamente conforme o esperado.

Entre 1980-1989, ou seja, antes do Plano de desestatização tocado em marcha a partir de 1990, o PIB nacional obteve um crescimento anual médio de 2,9\%. Já entre os anos de 1990 a 1999, isto é, após o começo das reformas estruturais, o crescimento médio anual baixou para 1,7\%; a inflação, comparando a série histórica de

\footnotetext{
<https://www.tjdft.jus.br/institucional/imprensa/noticias/2017/junho/juiza-do-tjdft-aponta-ilegalidade-em-cobranca-deingressos-diferenciada-entre-homens-e-mulheres>.

${ }^{11} \mathrm{Na}$ atualidade, voltou-se a debater as privatizações. No Rio de Janeiro, o Governador Luís Fernando Pezão (PMDB) está propondo a venda da CEDAE (Companhia Estadual de Águas e Esgoto) como forma de sanar as dívidas estaduais e incrementar a arrecadação. Discordando da saída para o rombo do erário local, PSOL/RJ e REDE/RJ se opuseram à venda, alegando em juízo, por meio de Ação Direta de Inconstitucionalidade, que "[...] a privatização produzirá apenas um alívio muito provisório nas contas estaduais". Ver: <http://justificando.cartacapital.com.br/2017/04/03/rede-e-psol-questionam-lei-que-autoriza-privatizacao-dacedae-no-rio/>. O saneamento das contas públicas é o mesmo argumento usado por José Ivo Sartori (PMDB) no Rio grande do Sul, que está defendendo a venda de três estatais: a CEEE, a Companhia Riograndense de Mineração e a Sulgás. Disponível em: $<$ http://gl.globo.com/rs/rio-grande-do-sul/noticia/governo-apresenta-dados-para-defender-pec-que-possibilita-privatizacao-deestatais.ghtml $>$. E para além do argumento técnico/econômico, as privatizações surgem como um meio alternativo de combate à corrupção, como defendeu recentemente o ex-presidente Fernando Henrique Cardoso. Ver: <http://veja.abril.com.br/politica/fhc-ve-politica-podre-e-defende-privatizacoes-contra-corrupcao/>.
} 
1980-1989 com o período entre 1990-1999, aumentou 6\% e a taxa de desemprego nesse período comparado também subiu. ${ }^{13}$ Os índices macroeconômicos de 1989-2000 (Tabela 1) de formação bruta de capital fixo e nível de crescimento per capita, demonstram o quão tímido foram os resultados atingidos.

\section{Tabela 1 - Índices macroeconômicos brasileiros entre 1989-2000}

\begin{tabular}{|c|c|c|c|c|c|}
\hline & $\begin{array}{c}\text { Taxa de } \\
\text { crescimento } \\
\text { (PIB) }\end{array}$ & $\begin{array}{c}\text { Taxa de } \\
\text { crescimento } \\
\text { per capita }\end{array}$ & $\begin{array}{c}\text { Investimento (\% } \\
\text { PIB) - Preços de } \\
1980\end{array}$ & $\begin{array}{c}\text { Taxa de crescimento } \\
\text { da FBKF (Formação } \\
\text { bruta de capital fixo) }\end{array}$ & $\begin{array}{c}\text { Taxa de desemprego } \\
\text { (Médias anuais pela } \\
\text { PME do IBGE) }\end{array}$ \\
\hline 1989 & 3,2 & 1,4 & - & - & 3,3 \\
\hline 1990 & $-4,4$ & $-5,5$ & - & - & 4,3 \\
\hline 1991 & 1,0 & $-0,6$ & 15,2 & $-1,8$ & 4,8 \\
\hline 1992 & $-0,5$ & $-2,1$ & 14,0 & $-8,6$ & 5,7 \\
\hline 1993 & 4,9 & 3,4 & 14,4 & 7,2 & 5,3 \\
\hline 1994 & 5,9 & 4,3 & 15,2 & 12,5 & 5,1 \\
\hline 1995 & 4,2 & 2,8 & 16,7 & 13,7 & 5,4 \\
\hline 1996 & 2,7 & 1,2 & 16,5 & 2,5 & 5,7 \\
\hline 1997 & 3,3 & 1,9 & 17,9 & 12,4 & 7,6 \\
\hline 1998 & 0,2 & $-1,1$ & 17,5 & $-1,8$ & 7,6 \\
\hline 1999 & 0,5 & $-0,5$ & 16,1 & $-7,0$ & 7,1 \\
\hline 2000 & 4,4 & 3,1 & 15,7 & Nd & \\
\hline
\end{tabular}

Fonte: Carcanholo (2005, p. 142).

Posto isso, pode-se concluir que o baixo desempenho dos indicadores econômicos foi essencialmente resultado do novo modelo de desenvolvimento econômico implementado no país naquele período? Não é tão simples de precisar. É difícil afirmar categoricamente que "sim”, que os resultados dos indicadores daquele período foram causados pela nova engenharia econômica aplicada. O ponto que dificulta resposta para a questão é onde apontar a relação de causa e efeito e com quais as variáveis estamos lidando. ${ }^{14}$ Em termos conjunturais, por exemplo, a década de 1980 foi marcada pela crise da dívida externa e pelo incessante combate à inflação. Um economista que defendesse a abertura comercial e financeira poderia justificar que os fracos resultados obtidos com a agenda econômica imposta não apresentavam uma pré-condição básica (ex. o baixo nível inflacionário). Logo, uma condição vital para que a agenda conseguisse produzir seus melhores efeitos não estava dada naquele momento. Uma alegação desse tipo seria razoável. Mesmo assim, a série histórica acima - período entre 1989-

\footnotetext{
${ }^{12}$ De acordo com Marcelo Carcanholo (2005, p. 12), uma das contrapartidas exigidas aos países que contraíam empréstimos com o FMI naquele período era de que os devedores deveriam se esforçar em manter um superávit primário e um déficit operacional de, no máximo, $2 \%$ do PIB, com o objetivo de não fazer com que suas economias descarrilhassem.

${ }^{13}$ Dados extraídos de Giambiagi e Moreira (1999, p. 13).

${ }^{14}$ Sobre causalidade no nível macroeconômico, já se tornaram clássicas as obras de Hoover (2001a, 2001b) sobre o assunto. Para uma discussão mais recente sobre o tópico, ver Reiss (2013) e Cartwright (2014).
} 
2000 - demonstra que os resultados continuaram tímidos mesmo após seis anos da implementação do Plano Real, ocorrida em 1994. De todo modo, independente de inclinações políticas ou econômicas, é razoável concluir que, à luz dos dados ou evidências, a estratégia de desenvolvimento econômico aplicada naquele período não correspondeu plenamente às expectativas..$^{15} \mathrm{Ou}$ seja, no mínimo, as evidências passadas não sugerem uma mera replicação de estratégia no futuro.

Voltando para o cenário jurídico, o caso das privatizações demonstra os limites da aplicação do receituário de Dworkin. Afinal, uma eventual privatização futura da PETROBRÁS não poderia ser respaldada apenas em casos passados. Mesmo que revestida de isonomia formal (o tratamento de um caso futuro vinculado a casos equivalentes passados), a avaliação desse tipo de caso é essencialmente consequencialista; não é uma discussão valorativa sobre indivíduos e suas condutas. Na década de 1990, a venda de estatais estiveram indissociavelmente envolvidas com a estratégia de desenvolvimento econômico que veio a ser implementada. As privatizações eram uma das condições estabelecidas pelo projeto de desenvolvimento brasileiro adotada nos anos 1990. Se o Estado deveria participar como indutor da economia e em que grau essa interferência deveria ocorrer estava na pauta diária do debate público daquele momento. ${ }^{16} \mathrm{Se}$, por ventura, uma nova proposta de venda de uma estatal como a PETROBRÁS vier à tona em um cenário futuro, esse discussão será novamente abordada. Talvez ela ganhe novos contornos, com novos elementos conjunturais, mas seu esqueleto permanecerá quase que intacto. Nessa discussão, talvez o mais sugestivo (e quem sabe óbvio) fosse, do ponto de vista prático, avaliar caso a caso, olhando para todos os indicadores à disposição, antevendo riscos de cartelização do setor ao qual a empresa a ser privatizada pertence etc. ${ }^{17}$ Olhar simplesmente para os balanços das empresas antes e depois desta ter sido privatizada tornaria a análise problemática. Afinal, nada assegura que outro tipo de atitude governamental que não a simples venda do patrimônio não poderia recuperar suas finanças. Além disso, mesmo que empresas privadas pratiquem ações sociais, isso não é compulsório ou passível de ser exigido por parte do poder público, algo que pode ocorrer com uma empresa pública como de fato ocorreu com a Vale do Rio Doce enquanto empresa pública.

Por mais que quiséssemos afastar a esfera jurídica desse debate, o judiciário foi motivado a se pronunciar, uma vez que as privatizações na década de 1990 foram judicializadas. O governo travou diversas batalhas judiciais

\footnotetext{
${ }^{15}$ Aliás, a relação dívida x PIB, uma das razões para a forma de desenvolvimento econômico adotada à época, só aumentou desde então. O montante que girava em torno de 37\% do PIB nacional no ano de 1994, alcançou o patamar de $76 \%$ em 2002 . Uma compilação dos dados pode ser conferida em: <http://terracoeconomico.com.br/evolucao-da-divida-publica-brasileira-desde1978-um-grafico-para-voce-refletir>.

${ }^{16}$ Ainda encontram-se disponíveis, na plataforma virtual Youtube, os comerciais de televisão promovidos pelo governo do então Presidente Fernando Collor de Mello em favor das privatizações.

${ }^{17}$ A justificativa legal, do ponto de vista interno do Direito, é oferecida na próxima seção.
} 
para conseguir vender seus ativos. ${ }^{18}$ As ações impetradas eram das mais diversas, versando ora sobre a forma dos leilões realizados, ora sobre o conteúdo da venda (sua pertinência). Portanto, juízes tiveram que oferecer razões jurídicas para a venda das estatais. Todos esses aspectos que estavam colocados à época no debate público, poderiam ser considerados enquanto os elementos nucleares que hoje comporiam, de acordo com a classificação de Shecaira e Struchiner, o polo substantivo da argumentação jurídica. Isso posto, retomemos mais uma vez ao argumento de Dworkin.

Há duas formas de interpretá-lo. Uma delas como um inevitável engessamento do magistrado para a tomada de decisão, dada às circunstâncias do caso. Uma vez que houve unicidade entre decisões transitadas em julgado sobre um mesmo tipo de caso, sua concepção torna-se problemática, em virtude de possíveis consequências diametralmente diferentes de seus precedentes. ${ }^{19}$ Por outro lado, se compreendido o argumento enquanto uma mera recomendação/advertência para que um juiz leia o que seus pares disseram sobre o mesmo assunto que ele julgará, para que ele se esforce ao máximo na busca da melhor solução que esteja em acordo com o texto constitucional, então isso não sugere, necessariamente, o uso de precedentes como fundamento para uma decisão desse tipo. Pois, como demonstra o exemplo debatido, as evidências acerca do modelo de desenvolvimento econômico dos anos 1990 não sugerem uma replicação cega de seu receituário, da qual a diminuição da influência estatal na composição do PIB e a venda de estatais fizeram parte.

Uma primeira crítica que pode suscitar sobre esse tipo de situação seria afirmar que tal matéria (venda de estatais) passa ao largo das atribuições do judiciário, uma vez que a venda de uma estatal é uma questão essencialmente de Estado. Isso seria uma questão eminentemente política; logo, não jurídica. Há problemas com esse tipo de crítica. Em primeiro lugar, o Direito toca a tudo e a todos, inclusive o Estado. É o Direito que confere juridicidade ao Estado e é a instância quem fiscaliza e impõe os freios formais da atuação estatal (ao menos, em tese). Em segundo lugar, como já dito anteriormente, o judiciário foi motivado a se pronunciar sobre as privatizações realizadas naquele período. Ações foram promovidas e argumentos jurídicos (ora mais institucionais, ora mais substantivos) tiveram que ser enfrentados a fim de assegurar as vendas defendidas pela União e pelos Estados da Federação que argumentavam em favor das vendas de suas empresas. Partidos políticos, entidades sindicais e Seccionais Regionais da Ordem dos Advogados do Brasil ingressaram com ações judiciais, questionando a constitucionalidade das vendas, alegando que as privatizações em massa acarretariam a perda da soberania nacional, uma vez que o Brasil perderia as reais condições de garantir o desenvolvimento econômico do

\footnotetext{
${ }^{18}$ Em A privatização do Brasil, Giambiagi e Pinheiro (1999, p. 32) documentam que só para a venda da Vale do Rio Doce, o a União precisou responder (e vencer) 217 ações judiciais.

${ }^{19}$ Como já advertiu Duxbury (2008, p. 154): “[...] frequentemente, é muito difícil definir que, seguindo um precedente, assim como partindo de um precedente, a decisão terá as consequências que os julgadores almejaram” (2008.p. 154).
} 
país, já que essa agenda poderia baixar dramaticamente a arrecadação. ${ }^{20}$ Ora, avaliar a correta decisão para esse tipo de caso passa ao largo do conhecimento do juiz, uma vez que ela depende - para adequada valoração - de um aporte técnico em Economia. Qualquer que seja o argumento, favorável ou contrário à privatização, dependerá, para sua robusteza e força, de premissas que fogem ao escopo teórico de um magistrado. Essa questão, por mais que perpasse princípios e valores consolidados na Constituição, inevitavelmente depende de auxílio das teorias econômicas em vigência. Portanto, não seria uma melhor alternativa amparar a decisão desse tipo de caso no melhor esquema teórico em economia à disposição no momento ${ }^{21}$

A decisão sobre um caso desse tipo - a privatização de uma estatal de tamanha envergadura como a PETROBRÁS - perderia sua força justificativa se ancorada meramente em casos passados. Mesmo se aceitássemos o receituário de Dworkin, aquilo que poderia vir a nos informar, de forma mais adequada, como a história poderia ser corretamente replicada buscando a concretização dos valores morais e políticos da carta constitucional, está fora do domínio estritamente legal. Portanto, torna-se inevitável o uso de teorias externas ao estrito domínio legal para auxiliar na melhor solução de um caso dessa magnitude.

\section{O USO DAS TEORIAS CONEXAS AO DIREITO PARA A RESOLUÇÃO DE CASOS LEGAIS}

Passemos agora ao modo pelo qual as teorias econômicas poderiam ser usadas para a resolução da hipótese formulada (a possibilidade de venda futura da PETROBRÁS), tendo como base o texto constitucional vigente.

De acordo com o art. $3^{\circ}$ da $\mathrm{CF} / 88$, constituem objetivos centrais do Estado brasileiro a construção de uma sociedade livre, justa e igualitária (inciso I), garantir o desenvolvimento nacional (inciso II) e erradicar a pobreza e a miséria, diminuindo as desigualdades sociais e regionais (inciso III). Nos três incisos elencados deste dispositivo constitucional, do ponto de vista prático, se desejamos de fato efetivá-los, o inciso II acaba funcionando como uma pré-condição ao demais. Afinal, é condição necessária para a erradicação da miséria, efetivando tais objetivos do Estado brasileiro fixados nos incisos I e III do art. $3^{\circ}$ o desenvolvimento nacional (inciso II). O desenvolvimento nacional não é um fim em si mesmo. Essa discussão, o que se entende por “desenvolvimento", é

\footnotetext{
${ }^{20}$ Entre 1998 e 2002, 39 Ações Diretas de Inconstitucionalidade foram impetradas no Supremo Tribunal Federal opondo-se as vendas das estatais vendidas. Nenhuma dessas ações prosperou. Boa parte delas sequer foi conhecida. Os dados podem ser conferidos em Oliveira (2005).

${ }^{21}$ Em economia, não há paradigma estabelecido. Na atualidade, há diversas correntes antagônicas acerca do modo como a ciência econômica deve ser abordada: marxistas, neoclássicos, neo-keynesianos, escola austríaca, neo-ricardianos, institucionalistas e póskeynesianos estão entre algumas das escolas de pensamento que vigoram nas universidades mundo afora. Um resumo das diversas concepções econômicas em disputa e a própria discussão metodológica acerca da natureza do fenômeno econômico pode ser encontrada em Hausman (2012).
} 
uma questão primordialmente econômica, uma vez que trata de como o país gera e administra seus recursos escassos, os distribui, quais medidas a serem tomadas para aumentar sua arrecadação, a produtividade, como multiplicar emprego e renda etc. ${ }^{22}$

Os argumentos em favor da redução da miséria são fundamentais e uma forma razoável de interpretá-los é - com base na nossa Carta nacional - enquanto um fim a ser perseguido com uma decisão que versaria sobre a diminuição da intervenção do Estado brasileiro na sua própria economia. Afinal, é disso que se trata, em última instância, a venda de uma empresa nacional de grande valor de mercado ou a estatização de determinada empresa privada: estratégias diversas de desenvolvimento nacional e que visam melhorar as condições materiais da vida dos cidadãos no médio e longo prazo. Todavia, o debate acerca do desenvolvimento nacional e de que forma alcançaremos tal objetivo é o meio para a concretização dos incisos I e III. Portanto, torna-se óbvio que o desfecho da questão dependerá do debate econômico a ser enfrentado. Se faz sentido esse argumento, surge então o problema de como legitimar o uso de uma teoria externa ao ordenamento jurídico e que não é pensada enquanto fonte legal. Para tal, passemos mais uma vez à inestimável contribuição à literatura nacional sobre a argumentação em Direito dos Professores Shecaira e Struchiner (2016).

Em Teoria, os autores, além de distinguirem os tipos de argumentação do cenário jurídico, diferenciaram os tipos de fontes jurídicas possíveis: as (a) formais e as (b) materiais. ${ }^{23}$ As primeiras são aquelas que englobam majoritariamente o campo de debate jurídico do cotidiano e que são focos de disputas nos tribunais: as leis, os precedentes ou práticas judiciais as quais os operadores jurídicos se remetem explicitamente quando sustentam suas argumentações. Ainda dentre as fontes formais, Shecaira e Struchiner elaboraram uma subdivisão interna dessas fontes. Há aquelas fontes tidas enquanto obrigatórias (leis, por exemplo). A estas, os profissionais da área jurídica são obrigados a mencioná-las, mesmo que para rejeitar sua eventual aplicação para o caso em disputa. Já a doutrina (jurídica), aquilo que a academia jurídica produz de material sobre o direito, seria o principal exemplo de fontes opcionais. Um advogado não é obrigado a mencionar determinado autor em uma sustentação oral ou petição, por exemplo; tampouco será censurado por deixar de fazê-lo. Na classificação de Shecaira e Struchiner, a doutrina fica adstrita à produção intelectual dos cursos de Direito. Com base nas divisões e subdivisões elaboradas por Shecaira e Struchiner, talvez seja importante incluir entre as fontes formais opcionais as teorias econômicas ou sociais, inflacionando o que se entende comumente por "doutrina" e, por consequência, aumentando o escopo de fontes formais opcionais.

\footnotetext{
${ }^{22} \mathrm{Na}$ literatura econômica, há uma diferença entre crescimento econômico e desenvolvimento econômico. Sobre as duas diferentes concepções - que não são necessariamente excludentes - há compreensões distintas a respeito do que se entende sobre elas. A título de exemplo, sobre crescimento econômico e suas diferentes correntes intelectuais, um bom resumo pode ser encontrado Aghion e Howitt (2009). Já sobre o desenvolvimento econômico, ver Hayami e Godo (2005) e Sunna e Gualerzi (2016).
} 
A primeira razão para justificar tal incorporação no escopo das fontes formais do direito é a dependência explicativa. Diversas leis fazem referência explícita a questões sociais ou econômicas. Enquanto os standardslegais procederem de tal forma, se reportando a aspectos externos ao domínio básico de formação intelectual do operador jurídico, é recomendável que as teorias que têm como objeto primeiro de investigação o conteúdo dessas leis possam ser reconhecidas enquanto fontes opcionais do direito para a melhor elucidação dos casos. No exemplo aqui discutido, o que se entende por "desenvolvimento nacional", o que o inciso II do art. $3^{\circ} \mathrm{da} \mathrm{CF} / 88$ determina no nível do dever-ser (ou prescritivo) é uma orientação, fixada em termos sintáticos, a ser perseguida pela República. Mas o seu conteúdo foge ao escopo exclusivamente legalista. Se fosse possível construir um sistema de justiça cujas convenções não fizessem qualquer referência a ciências externas ao direito, talvez isso fosse desnecessário. Como não o é, o reconhecimento de tais teorias enquanto fontes formais opcionais do sistema jurídico é uma razoável alternativa.

No exemplo ficcional aventado neste trabalho - a possibilidade de judicialização da privatização de uma estatal do porte da PETROBRÁS - uma saída possível para o caso poderia ser a criação de uma comissão especial para auxiliar no melhor julgamento do caso. Assim, com base em um relatório técnico, apurando as possíveis consequências de uma venda da estatal, deveria o magistrado se perguntar, com base no relatório, se a venda é uma medida que auxiliará o Estado brasileiro a viabilizar a efetivação dos incisos I e III do art. $3^{\circ}$ da CF/88. Mas note que mesmo essa saída não é isenta de problemas: afinal, quem comporia tal comissão? Quais seriam os critérios para sua composição? Ela seria plural, incorporando as diversas correntes antagônicas em economia, ou seria predominantemente composta por um pensamento único? De qualquer modo, o problema em questão, por mais complicada que seja sua solução (solução esta que não cabe aqui especular), não exclui o fato de que uma decisão desse quilate torna-se extremamente enfraquecida se sua justificativa for meramente institucional - para nos valer da classificação de Shecaira e Struchiner.

Por fim, outro problema que essa proposta suscitaria é que a inserção de teorias externas ao Direito poderia tornar o sistema disfuncional, dando ampla margem de manobra para a decisão judicial. De fato, o excesso de fontes jurídicas é problemático e é uma consequência dessa proposta. Além do mais, como já dito, a própria Economia - que seria a ciência auxiliar no caso aqui trazido como exemplo - não possui um paradigma estabelecido, dificultando uma apreciação correta acerca de qual ou quais correntes deveriam ser usadas como ferramentas auxiliares a serem usadas na solução do caso. Além disso, dentre as fontes formais já disponíveis, elas são muitas e, por vezes, conflitantes (são vagas, dando margem para uma disputa por seus significados). Entretanto, no tocante à doutrina, a própria prática jurídica contemporânea convive com uma gama considerável

\footnotetext{
${ }^{23}$ Para os propósitos do meu argumento, me deterei apenas às fontes formais.
} 
de concepções doutrinárias divergentes. Na esfera penal, ou civil, há diferentes doutrinas sobre os mesmos tópicos jurídicos. ${ }^{24}$ Por vezes, profissionais do Direito usam doutrinas para sustentar seus argumentos. Algumas são de larga aceitação em tribunais, coadunando com a jurisprudência vigente, outras são minoritárias, o que não significa que não sejam usadas ou que não existam. $\mathrm{O}$ uso da doutrina legal na prática jurídica é o melhor exemplo para assegurar que o reconhecimento da literatura econômica como fonte opcional, ao menos no caso aqui avaliado, não teria nenhuma particularidade. Portanto, essa seria uma razão adicional para encaixar tais teorias enquanto fontes formais opcionais do Direito.

\section{CONCLUSÃO}

Este artigo visou, por meio de um caso hipotético, demonstrar a limitação da estética dworkiniana; seu modelo (tal qual o raciocínio com base em precedentes) não tem como ser aplicado para qualquer caso. Sustentou-se a exigência de elementos externos ao Direito para a melhor solução do caso proposto. Mesmo aquilo que, por ora defendido, traga como implicação o inflacionamento sistêmico do que poderia ser aceito enquanto fonte formal (e opcional) do Direito, o argumento sustentou a inevitabilidade desse tipo de análise para a melhor solução de casos que se remetam a elementos externos ao domínio de formação jurídica. Se quisermos efetivar os fundamentos da República como determina o art. $3^{\circ}$ de nossa Constituição, é necessário considerar os meios adequados (o que se entende por "desenvolvimento nacional" e qual a melhor forma de alavancar tal desenvolvimento) para efetivar seus fins almejados (redução da miséria e justiça social).

Uma possibilidade concreta para melhor lidar com questões dessa natureza seria exigir nos concursos para a magistratura disciplinas que, até então, são requisitos apenas aos que pretendem a diplomacia (história econômica geral, economia brasileira entre outras disciplinas). Isso daria maior autonomia ao julgador. Mesmo assim, isso não afastaria a pertinência em habilitar o uso dessas teorias externas ao Direito enquanto fontes opcionais. Afinal, há progresso nessas ciências.

Eventuais tentativas de blindar o ativismo judicial não podem ser desculpas para o Direito dar às costas para ciências que possam the auxiliar na melhor resposta possível para os casos concretos. Afinal, o ativismo judicial independe do reconhecimento de novas fontes formais do direito para sua efetivação prática. Portanto, se quisermos levar o Direito a sério, como dizia Dworkin, então não há razão para invalidar o uso do melhor aparato

\footnotetext{
${ }^{24}$ No cenário penal, são diversos exemplos de divergências doutrinárias. Um destes exemplos é a diferença entre a concepção bipartida de "crime" e a perspectiva tripartida de "crime". Dentre os defensores da primeira perspectiva estão Jesus (1980) e Dotti (2005). Já a segunda corrente é defendida por Toledo (1999) e Nucci (2013) entre outros. E na esfera cível, um exemplo emblemático de concepções plurais que tentam incorporar as novas formas de relacionamento é o conceito de "família". Uma compilação das diversas formas distintas do que se entende por família, bem como sua aplicação prática na esfera legal, ver Maluf (2010).
} 
teórico à disposição para a resolução dos casos. E, no caso hipotético aqui debatido, ficou clara a exigência de elementos técnicos externos do domínio estritamente legal. Espera-se que este trabalho suscite novas discussões sobre a argumentação jurídica e sobre o que deveria ser reconhecido enquanto de fontes formais opcionais, visto que o artigo abordou um único caso em específico.

\title{
DWORKIN'S CHAIN ROMANCE AND THE BRAZILIAN PRIVATIZATIONS: IN DEFENSE OF THE RECOGNITION OF ECONOMIC THEORIES AS OPTIONAL FORMAL SOURCES OF THE LAW
}

\begin{abstract}
This paper argues that judicial decisions justified through previous cases cannot be replicated for every case. It is claimed that this kind of legal reasoning can lead to different consequences than those which have been expected. The paper contrasts Ronald Dworkin's so-called "chain romance" metaphor, claiming that the use of theories attached to the law to aid in the resolution of such legal case is explicably superior. Having said this, it is argued that those theories attached to the Law should, in the same way as it occurs in Legal Scholarship, be recognized as optional Sources of Law.
\end{abstract}

Keywords: Ronald Dworkin; Chain Romance; Legal Scholarship; Sources of Law.

\section{BIBLIOGRAFIA}

AGHION, Philippe.; HOWITT, Peter. The economics of growth. Cambridge: The MIT Press, 2009.

CARCANHOLO, Marcelo. A vulnerabilidade econômica do Brasil. São Paulo: Ideias e letras, 2005.

CARTA CAPITAL. Rede e PSOL questionam lei que autoriza privatização da CEDAE no Rio. Carta Capital, 25 jun. 2017. Acesso em: 26 jun. 2017. Disponível em: <http://justificando.cartacapital.com.br/2017/04/03/redee-psol-questionam-lei-que-autoriza-privatizacao-da-cedae-no-rio/>.

CARTWRIGHT, Nancy. Causal inference. In: CARTWRIGHT, Nancy; MONTUSCHI, Eleonora. Philosophy of social Science: a new introduction, p. 308-326. Oxford: Oxford University Press, 2014.

COLEMAN, Jules. Efficiency, auction and exchange: philosophical aspects of the economics approach of law. California Law Review, v. 68, n. 221, p. 220-249, 1980. Market, morals and the law. Cambridge: Cambridge University Press, 1988.

CROSS, Frank; LINDQUIST, Stefanie. Empirically testing Dworkin's chain novel theory: studying the path of precedent. New York Law Review, v. 80, p. 1157-1206, 2005. 
DAKOLIAS, Maria. The judicial sector in Latin America and the Caribbean: elements of reform. In: World Bank Technical Paper 319. The World Bank, Washington, 1996.

DOTTI, René. Curso de Direito Penal: Parte Geral, 2ª Edição. São Paulo: Forense, 2005.

DUXBURY, Neil. Jurists and judges: an essay on influence. Oxford: Oregon, 2001. The nature and authority of precedent. Cambridge: Cambridge University Press, 2008.

DWORKIN, Ronald. Uma questão de princípio. São Paulo: Martins Fontes, 2001. O império do direito. São Paulo: Martins Fontes, 2007. Justiça de toga. São Paulo: Martins Fontes, 2010.

ENDICOTT, Timothy. Vagueness in law. Oxford: Oxford University Press, 2000.

FUKASUKU, Kiichiro; PINHEIRO, Armando Castelar. A privatização do Brasil: o caso dos serviços de utilidade pública. Rio de Janeiro: BNDES, 1999.

GARROTE, Bruno. Objetividade e interpretação: o debate meta-filosófico através do debate entre R. Dworkin e S. Fish. São Paulo: Liberars, 2017.

G1 PORTAL DE NOTÍCIAS. Governo apresenta dados para defender PEC que possibilita privatização de estatais. G1 Portal de Notícias. Acesso em: 23 mai. 2017. Disponível em: <http://g1.globo.com/rs/rio-grandedo-sul/noticia/governo-apresenta-dados-para-defender-pec-que-possibilita-privatizacao-de-estatais.ghtml>.

HARRISON, Jeffrey. Law and economics. St. Paul: West Group, 1995.

HAUSMAN, Daniel. Philosophy of economics. Stanford Encyclopedia of Philosophy, 2012. Disponível em: $<$ http://plato.stanford.edu/entries/economics/>. Acesso em 04 abr. 2016.

HAYAMI, Yujiro.; GODO, Yoshihisa. Development economics: from the poverty to the wealth of nations. New York: Oxford University Press, 2005.

HOOVER, Kevin. Causality in macroeconomics. Cambridge: Cambridge University Press, $2001 \mathrm{a}$. The methodology of empirical macroeconomics. Cambridge: Cambridge University Press, $2001 \mathrm{~b}$.

JESUS, Damásio. Direito Penal, 10 Vol., 2ª Edição. São Paulo: Saraiva, 1980.

JORNAL FOLHA DE SÃO PAULO. Privatização: advogados apontam supostas irregularidades cometidas pelo BNDES no processo de desestatização. Folha de São Paulo, 02 mai. 1997. Acesso em: 20 jun. 2017. Disponível em: <http://wwwl.folha.uol.com.br/fsp/brasil/fc020506.htm>.

KATZ, Avery. Foundations of the economic approach to law. Oxford: Oxford University Press, 1998.

KORNHAUSER, Lewis. The economic analysis of law. The Stanford Encyclopedia of Philosophy, 2011. Disponível em: <https://plato.stanford.edu/entries/legal-econanalysis/>. Acesso em: 24 jun. 2017.

MALUF, Adriana. Novas modalidades de família na pós-modernidade. Tese (Doutorado em Direito) - 


Faculdade de Direito da USP, 2010. Disponível em:
<file://C:/Users/ASUS/Downloads/TESE_COMPLETA_PDF_ADRIANA.pdf>.

NUCCI, Guilherme. Manual de Direito Penal: parte geral - parte especial, $9^{a}$ Edição. São Paulo: Revista dos Tribunais, 2013.

OLIVEIRA, Vanessa. Judiciário e privatizações no Brasil: existe uma judicialização da política? Dados, v. 48, n. 3, p. 559-587, 2005.

PINHEIRO, Armando.; GIAMBIAGI, Fabio.; GOSTKORZEWICZ, Joana. O desempenho macroeconômico nos anos 90. In: GIAMBIAGI, Fabio.; MOREIRA, Maurício. A economia brasileira nos 1990. Rio de Janeiro: BNDES, 1999.

POSNER, Richard. The economics of justice. Cambridge: Harvard University Press, 1981.

Economic analysis of law. New York: Aspen, $9^{\text {th }}$ Edition, 2014.

REISS, Julian. Philosophy of economics: a contemporary introduction. New York: Routledge, 2013.

REVISTA VEJA. FHC vê política "podre" e defende privatizações contra corrupção. Revista Veja, 22 jun. 2017. Acesso em: 23 jun. 2017. Disponível em: <http://veja.abril.com.br/politica/fhc-ve-politica-podre-e-defendeprivatizacoes-contra-corrupcao/>.

SHECAIRA, Fábio. Legal scholarship as a source of law. London: Springer, 2013.

SHECAIRA, Fábio; STRUCHINER, Noel. Teoria da argumentação jurídica. Rio de Janeiro: Contraponto, 2016.

SOLOW, Arthur. Evolução da dívida pública brasileira desde 1978. Terraço Econômico, 2017. Acesso em: 25 jun. 2017. Disponível em: <http://terracoeconomico.com.br/evolucao-da-divida-publica-brasileira-desde-1978um-grafico-para-voce-refletir>.

SUNNA, Claudia.; Gualerzi, Davide. Development economics in the twenty-first century. New York: Routledge, 2016.

TRIBUNAL DE JUSTIÇA DO DISTRITO FEDERAL. Juíza mantém preço diferenciado de ingresso, mas aponta ilegalidade na forma de cobrança. Sítio virtual do Tribunal de justiça do Distrito Federal. Acesso em: 25 jun. 2017. Disponível em: <https://www.tjdftjus.br/institucional/imprensa/noticias/2017/junho/juiza-dotjdft-aponta-ilegalidade-em-cobranca-de-ingressos-diferenciada-entre-homens-e-mulheres $>$.

WILLIAMSON, John. Latin America adjustment. Institute for International Economics. Washington D.C., 1990.

Trabalho enviado em 23 de janeiro de 2018.

Aceito em 21 de março de 2018. 